\title{
Experiences and Challenges of Promoting Pro-Poor and Social Inclusion Initiatives in User Group Forestry
}

\author{
Bimala Rai Paudyal, Peter Neil and Gaia Allison \\ Livelihoods and Forestry Programme, Nepal, \\ Email: b-rai@lfp.org.np
}

\begin{abstract}
Community Forestry has tremendous potential to reduce poverty and promote social inclusion in rural communities by improving the livelihoods of the poor and excluded, in particular the livelihoods of women, dalits and disadvantaged ethnic groups. However, there exists a large gap between the potential of the programme and its achievements in reality. Addressing this gap demands strategic interventions, including a careful analysis of barriers to inclusion and the promotion of pro-poor and socially inclusive programmes and monitoring. The paper argues that Community Forestry would better contribute to poverty reduction and social inclusion if support to user groups were focused on at least three specific (and interrelated) domains of changes. These can be identified as: increasing the access of the poor and excluded to livelihood assets; strengthening the organisation, voice and agency of the poor and excluded; and advocating for the development and enforcement of pro-poor and socially inclusive policies and institutions.
\end{abstract}

Key words: community forestry, social inclusion, livelihoods, gender, equity

\section{INTRODUCTION}

This paper attempts to document the significance of a shift in strategic approach towards the promotion of pro-poor and social inclusion initiatives in the forestry sector of Nepal. The past few years have seen a growing realisation among national policy makers and donor programmes alike that the objectives of poverty reduction, social inclusion and forest management need to be reconciled if the poor and socially excluded people are to benefit from environmental management programmes (Sunderlin et al., 2005). The Tenth Five Year Plan of His Majesty's Government of Nepal (HMGN) emphasises the importance of forestry in people's livelihoods and its potential as a means of poverty reduction. The plan specifically notes that activities should be targeted to the poor and excluded to ensure that they have opportunities to improve their livelihoods ${ }^{1}$.

Nepal has been a pioneer in developing and promoting Community Forestry $(\mathrm{CF})$, which focuses on establishing Community Forest User Groups (CFUGs) as local resource management institutions. $\mathrm{CF}$, now operating

1 A livelihood comprises the capabilities, assets and the activities, and the access to these mediated by policies and institutions that together determine the living gained by the individual or households (DFID, 1999). in all 75 districts of the country, has proven to be effective in managing and conserving forests where local people are dependent on the forests for their daily sustenance. As of December 2005, there were 14,277 CFUGs managing $1,185,565$ hectares of forest area involving 1,635,664 households all over Nepal (CFD, 2005). CFUGs have not only contributed to increase availability of forest products, but have also generated a significant amount of income locally (Kandel and Subedi, 2004; Kanel, 2004; Kanel and Niraula, 2004). This shows that $\mathrm{CF}$ has great potential to reduce poverty and promote social inclusion in rural communities through the improvement of the livelihoods of the poor and excluded, in particular women, dalits and disadvantaged janajati ${ }^{2}$. However, the actual realisation of the potential has remained a challenge. Rather, there is growing evidence that the poor women, dalits and janajati, have been excluded from the process and their interests have been consistently

2 Dalit here refers to the so-called lower caste and 'untouchables', according to the Hindu caste hierarchy. Janajati refers to minority ethnic groups who are disadvantaged in terms of access to opportunities, resources and voice (LFP 2005a). 
marginalized (Lama and Buchy, 2002; Pokharel and Nurse, 2004; HURDEC, 2004; Rai, forthcoming).

With the increasing realisation that unequal economic and social relations between economic and social groups that dominate village affairs in rural communities also prevail in the group dynamics of CFUGs resulting in inequity and social exclusion, there has been a move towards supporting and specifically promoting pro-poor and social inclusion initiatives in the forestry sector. This paper presents an example of such a move.

\section{CONCEPTUALISING POVERTY AND SOCIAL EXCLUSION ISSUES IN FOREST MANAGEMENT}

\section{Understanding of Poverty and Social Exclusion}

Poverty in Nepal continues to be a rural phenomenon and substantial disparities exist across ecological zones, development regions, caste, ethnicity and gender. The average rural income is 2.7 times lower than the average urban income, indicating severe inequality between rural and urban populations (CBS, 2004). Within the rural population, substantial disparities also exist in terms of caste, ethnicity and gender. Low social and economic status usually (but not always) reinforces each other; lower caste groups (such as Kami, Damai, Sarki) are often poor and also socially excluded. Similarly, the majority of those living in remote (and less accessible) areas are also the ones who are economically poor and socially excluded ${ }^{3}$. Inequality is significant in terms of economic status, human development indicators and political participation.

Social exclusion is a process by which certain sections of communities are denied access to resources and opportunities around them, resulting in the lack of assets, capabilities and voices for self-development and social dignity (Bhalla and Lapeyre, 1997). The generic situation of poverty and social exclusion that prevails in

3 "Socially excluded groups" are herein defined as communities and people living in remote areas, poor households, women, dalits and disadvantaged janajati. communities also affects development stemming from the forest sector and shapes its impact.

In terms of forest management, exclusion can be understood as a process by which poor, women, dalits and janajati (referred as poor and excluded people) have denied access to membership in user groups, participation in decision-making processes and thus are unable to access benefits derived from it (LFP, 2005a). Such inability of poor and excluded people to effectively make claims for their membership, to participate effectively and benefit proportionately from forest management is often caused by their economic and social relations and institutional barriers including inequitable rules and regulations of the institutions with which they are involved (ibid). Pro-poor and social inclusion initiatives involve identifying and removing these economic, social and institutional barriers that cause poverty and social exclusion.

\section{Class, Caste and Gender Specificity of Forest Resource Use}

The village economy in Nepal is critically dependent on the local agricultural and natural resource base. Though there are numerous variations in the overall system within the country, the production system is based on a combination of crop production, livestock rearing and utilisation of forest resources throughout rural Nepal. Common forests are vital sources of fuelwood, fodder, leaf litter, grazing land, fruits and fibres, building materials, medicines and herbs. Land-poor households also generate small incomes by selling forest-based products, such as fuelwood, leaf plates, mats and baskets. These forest products provide diversity to the rural economy and security when times are difficult (Agarwal, 1992; 1997). Though all rural households use forests for their livelihoods, the dependency on common forests to sustain livelihoods is greater among the poor and dalit households who own less private land (Rai, forthcoming).

Over and above such class and caste specificity, forest resource use has specific gender dimensions. Women and children, especially girls, are the main users of many forest products since they are primarily responsible for collecting fuel and fodder 
and many other products used for home consumption. Though highly time consuming, these tasks are unavoidable because of the unavailability of any other substitutes. Thus, changes in forest resource availability can have a direct impact on the livelihood and work pattern of women and children. In contrast, it is generally men who control decisions about the management of the resources, whether private or common. Frequently, their decisions do not reflect the needs and priorities of women who are the main resource users (Agarwal, 2000, 2001 and 2002; HURDEC, 2004).

\section{Barriers to Inclusion}

There has been some progress in addressing the livelihood needs of the poor and socially excluded, most importantly dalits and women, through their participation in CFUG under $\mathrm{CF}$. However, there still exists a wide gap between the expectation and the achievements of the programme in reality. Economic condition, caste identity and gender relations constrain the poor, women and disadvantaged caste and ethnic groups to make claims for membership, participation and access to benefits obtained from CFUGs. Exclusion from membership is the most important issue, especially when all assistance and interventions of service providers $^{4}$ are channelled through these user groups. Exclusion from membership not only results in these peoples' exclusion from participation and access to forest products, but also to access other non-forest benefits generated by CFUGs or provided by service providers through the groups.

Among the members, formal and non-formal institutional and social mechanisms often inhibit the poor in general and dalits, women and janajati in particular from being represented in their group's Executive Committee (samiti in Nepali) and from participating effectively in decision-making processes. Several studies highlight the constraints faced by the poor, dalits and women in being represented in samiti, in attending meetings regularly and influencing decisions in their favour. In terms of representation, poor and dalit households usually have limited access to education, limited leadership qualities and low confidence levels. They also tend to lack selfawareness, motivation and resources (Rai, forthcoming). These are basic access criteria, unofficially required in order to become a representative on the samiti. Thus, many from these groups are reluctant to even offer their candidacy.

Some gender-specific constraints that affect the interests and ability of women to represent themselves and participate effectively in decision-making include an absence of issues that are of direct concern to them, inappropriate venues and timing of meetings, lack of time because of the fulfilment of reproductive and productive roles, restricted mobility, a general preference for men to participate wherein one member from a household is invited, and societal norms which curtail their effective representation and participation in public forums like that of assemblies and samiti (Lama and Buchy, 2002; Zanetell and Knuth, 2004).

In addition, attitudes towards the poor, women and dalits discourage their participation. Common prejudices include the consideration of poor and dalits as being incapable of dealing with official matters and women as having short time horizons and being incapable of managing forests effectively (Rai, forthcoming). The lack of voice and influence in decision-making results in their inability to claim an equitable share of benefits derived from the management of the forest area. Forest policies and programmes are often seen as having failed to reach and benefit these groups because of the lack of acknowledgment of the specific constraints that these groups face and because of the lack of interventions specially designed to address these constraints.

\footnotetext{
4 "Service providers" here refers to all organisations and civil societies (including government organisations, donors, NGOs, federation and networks of users) that have been providing pre- and postformation support to Forest User Groups.
} 


\section{A SHIFT OF FOCUS: STRATEGIES FOR PRO-POOR AND SOCIAL INCLUSION}

\section{The Concepts}

The poor and excluded people face specific constraints resulting in the lack of access to information, resources and opportunities, in turn determining their ability to participate and benefit from any development interventions. To address issues of exclusion such as this, it is important to understand the processes by which people are excluded. People are excluded by institutions and behaviour that reflect, enforce and reproduce prevailing social attitudes and values, particularly those of the powerful groups in society (DFID, 2005a). Many practices of social exclusion, like that of caste and gender disparities, are culturallybased and are perpetuated as such (Andersen and Siim, 2004). This implies that the issue of exclusion cannot be addressed effectively unless cultural barriers of inclusion are recognised and those excluded are empowered to remove those barriers. Social inclusion and empowerment have complementary roles reinforcing each other (see Figure 1).

Figure 1: Complementary role of social inclusion and empowerment for inclusive outcomes

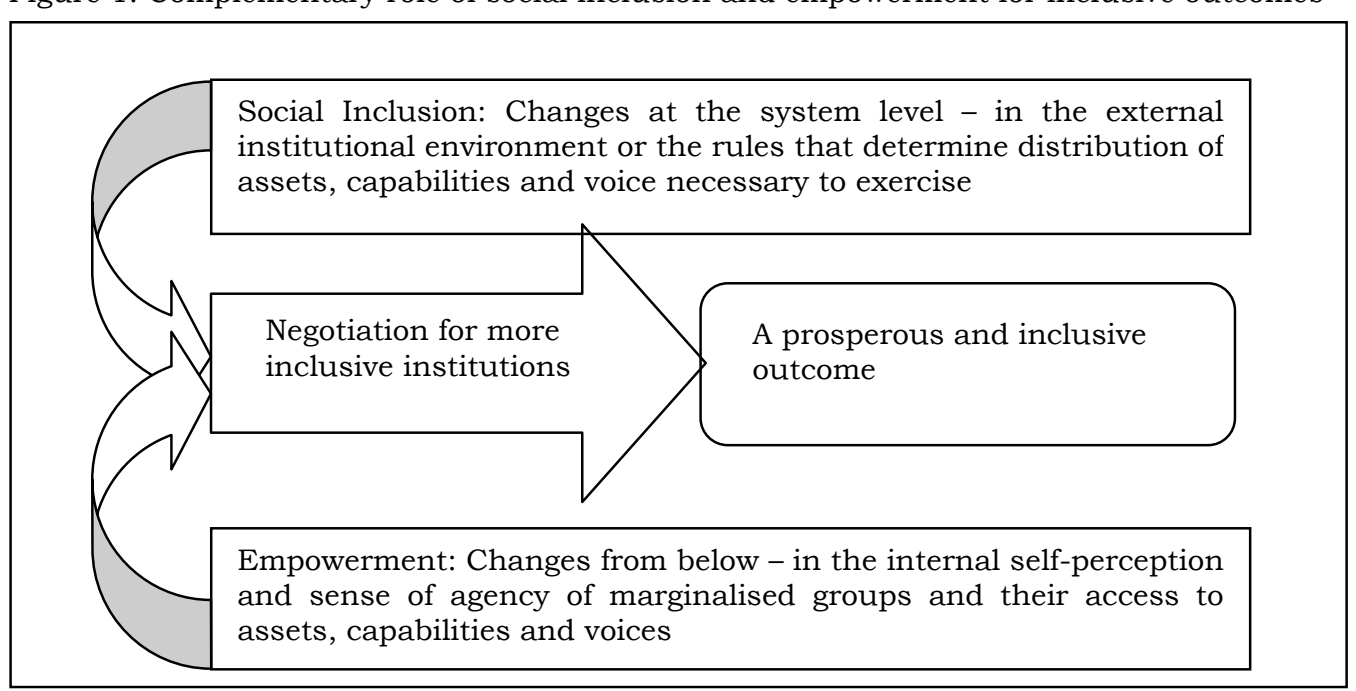

As the figure indicates, social inclusion is the removal of institutional barriers and the enhancement of incentives to increase the access of diverse individuals and groups to development opportunities.

It attempts to bring about changes at the systemic level and focuses on the development and implementation of rules that determine the distribution of assets, capabilities and voice in decision-making. In terms of forest management, this is specifically carried out to make the institutional environment conducive for the effective participation of poor and socially excluded groups and the equitable sharing of benefits. This involves making the policies, constitutions and operational plans of user groups and decisions on benefitsharing more responsive to the needs and priorities of the poor and excluded. In contrast, empowerment attempts to create changes from below through increasing the flow of assets, access to services, selfawareness, organisation and effective mobilisation of resources so that the poor and socially excluded groups are able to claim their rights of equitable access to assets, capabilities and voice.

Empowerment can be of two types. Livelihood empowerment focuses on the enhancement of the assets and capabilities of poor men and women to function and can be measured in terms of increased and sustained flow of assets capabilities. On the other hand, mobilisation focuses on organising and engaging the poor and excluded to influence the institutions that affect their livelihoods and hold them 
accountable. The complementarities of social inclusion and empowerment are the basis for designing and implementation of interventions for pro-poor and socially inclusive outcomes of forest management. Social mobilisation is key to the promotion of both empowerment and social inclusion.

\section{Livelihoods and Social Inclusion Framework}

The key feature of the Livelihoods and Social Inclusion (LSI) framework is that it enables active targeting and focus on three interrelated domains of change for programme design and monitoring. They are:

- Assets and access to services;

- Voices, influence and agency; and

- Rules of the game.
The framework focuses on the impact and processes in these three domains of change (see Figure 2). The framework is based on the understanding that change occurring in only one of these three domains will have less impact on the livelihoods of the poor and excluded than change that occurs in all three domains (DFID, 2005b).

As an example, in forest management, access to assets by the poor and excluded may be increased temporarily by providing increased amounts of forest resources, by increasing their access to employment created by forests or by providing them financial resources and skills for forestbased income generation. However, unless and until poor people can claim their rights to participate in decision-making and influence the policies and practices of forest management for their benefit, there will be

Figure 2: LSI analytical framework: process and outcomes of three domains of change

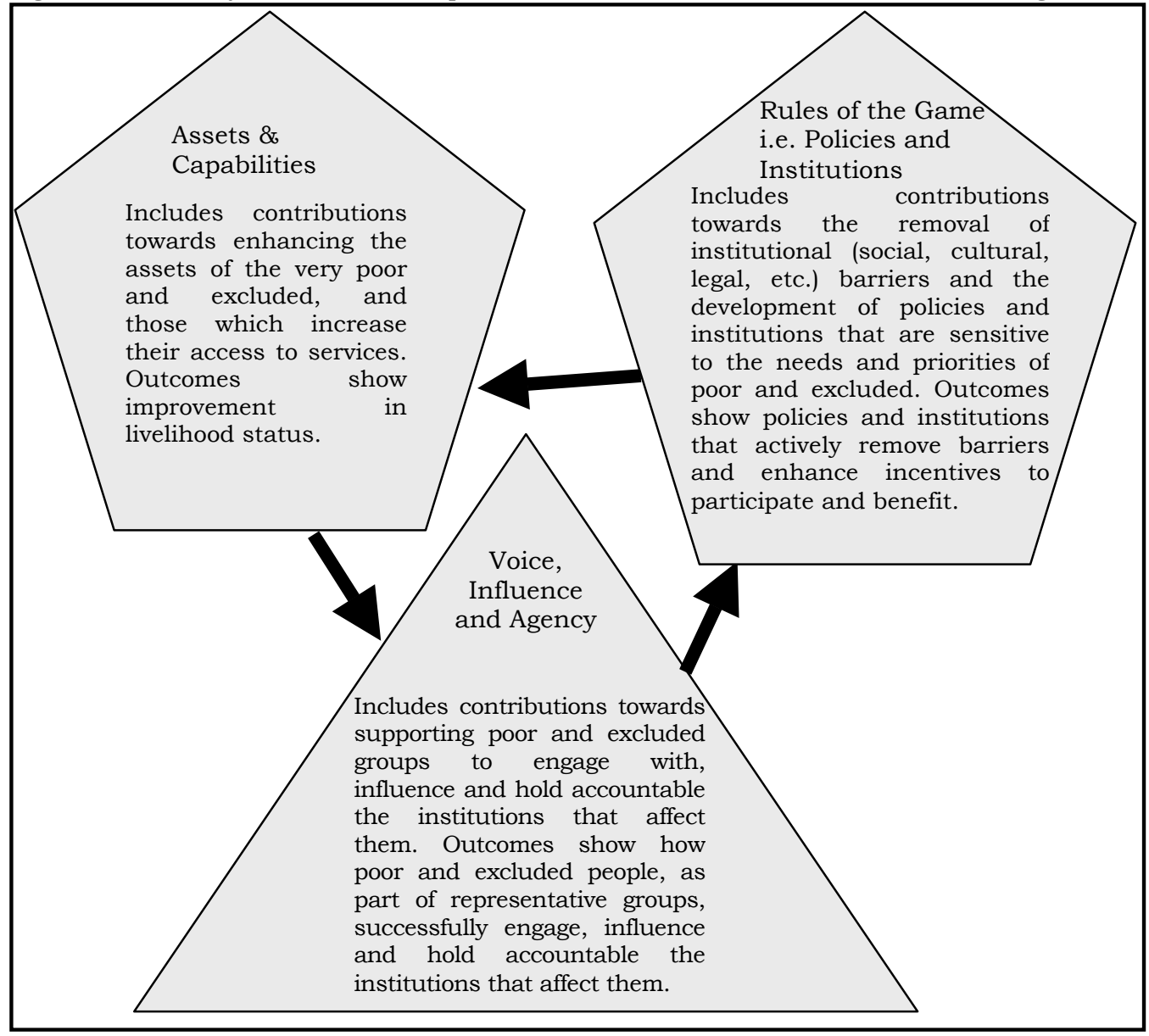


no sustainable improvement in livelihoods; people will not be empowered and social exclusion will remain. Processes to increase assets and access to services; to increase voice, influence and agency; and to change the rules of the game are all interlocking, and the arrows in the framework diagram represent unidirectional change. In other words, meaningful and sustainable change in each domain cannot happen without change in the other domains, and change in one domain leads to change in the others.

Figure 2 illustrates the significance of these three interrelated domains of change in creating meaningful and sustainable impact on livelihoods of poor and excluded. This can be illustrated as follows:

a) In order to change the discriminatory and exclusionary rules in a way that will increase the access of poor and excluded people, either through their own representative organisations or as part of coalitions for change, these groups must have voice and their agency must be able to use them to influence more inclusive policies and institutions. Discriminatory and exclusionary rules are created and perpetuated because they benefit those who hold power. Rules do not change on their own; neither do those who hold power and developed the rules change them easily. Removing institutional barriers and developing and enforcing pro-poor and social inclusive policies, rules and norms can take years of intelligent advocacy, influencing and lobbying.

b) In order for poor and excluded people to gain greater access to assets and services, the rules of the game must change in their favour. The reason that exclusion causes and perpetuates poverty is that exclusionary and discriminatory rules of the game deny certain groups of people access to those conditions and assets that will help them rise out of poverty. Only when the rules change to be more equitable and just will the livelihood status of poor and excluded people improve in a sustainable manner.

c) In order for poor and excluded people to meaningfully engage, influence and hold accountable the institutions that affect them, they must have the capacity to voice their rights, to form effective representative organisations and to forge coalitions for change. Illiterate, ill, starving, isolated and poverty-stricken people cannot do this; they need assets and access to services.

To achieve a sustainable and inclusive outcome, it is thus important that programmes and innovations should achieve an appropriate balance in terms of efforts and resource allocations in all three domains of change.

\section{FEATURES OF WORK WITH THE POOR AND EXCLUDED5}

\section{Inclusive Targeting Approach}

Undoubtedly, encouraging poor and socially excluded people to become interested enough to participate and to access those resources that are available is a challenge.

On the one hand, it is important to work with the poor and excluded through social mobilisation so that they participate effectively and claim a share of the benefits and on the other hand, more work is needed to influence the elites and to identify champions or agents of change within communities and elicit their support.
Reaching the poor and excluded thus requires an honest examination of equity in distribution of efforts and resources based on organisations' and practitioners' own attitudes and practices.

"Inclusive targeting" means that the activities need to balance the targeted support specific for poor and excluded groups with other activities that are of benefit to the community as a whole. This is particularly the case in relation to many forest management activities that necessitate the understanding and

${ }^{5}$ This section and those that follow are based on the experience of Livelihoods and Forestry Programme (LFP), a bilateral aid programme of HMGN and the UK Government's Department for International Development (DFID). The programme has a direct presence in 15 districts ( 3 in the Terai and 12 in the mid-hills). 
participation of the whole community. In working with the whole community, however, it is important to ensure that a greater proportion of benefits from interventions reaches the poor and excluded. Similarly, where specific and active targeting of poor and excluded households takes place, it is important to ensure that all members of communities are aware of why such targeting is important, how the identification of targeted households/communities took place, etc. This process needs to be managed so as not to increase tensions within communities and as part of a longer-term strategy to raise awareness about the needs of the poor and excluded.

\section{Tools for Better Targeting: CFUG} Categorisation and Well-being Ranking

The Livelihoods and Forestry Programme (LFP) is promoting a range of tools and methods to identify and help the poorest and most excluded to achieve better livelihoods. Among these, the CFUG Categorisation Tool and participatory Well-being Ranking are extensively used and have been found effective for better (and active) targeting of the poor and excluded. The CFUG Categorisation Tool helps to classify user groups according to their institutional, livelihoods, poverty and forest management status (LFP, 2005b). It identifies the priority areas of support required by the user groups, especially for their own planning efforts. It also helps to prioritise the investments so that capabilities, accountability and the commitment to address the issues of social exclusion can be strengthened in CFUGs in a more focused way. However, as in other participatory methods, the effectiveness of the CFUG Categorisation Tool also depends on the skills of the facilitators.

The Participatory Well-being Assessment has been used to identify the poor and excluded within groups wherein group members themselves develop the criteria, discuss and analyse their own conditions of poverty. Similar to the CFUG Categorisation, the effectiveness of the tool to identify the real poor depends on the skills of the facilitator, the process followed and the amount of time spent on triangulation. LFP encourages user groups to undertake the process of the Wellbeing Assessment themselves but currently they lack the expertise and skills required for this.

Tole Groups: Increasing the Voice and Influence of Poor and Excluded People in User Groups

\section{Significance of the 'tole' concept}

Although most forestry programmes and projects now encourage 'bottom-up' planning processes that are inclusive, CFUG executive committees often do not consider the needs and aspirations of the poor and excluded people. Many CFUGs include large numbers of households in scattered hamlets (called "toles" in Nepali), and it is difficult to ensure the participation of all of the poor and excluded in the decision-making processes of the group.

Significant numbers of poor and excluded households are not members of the local CFUG for various reasons, including high membership fees, a lack of access to information, and a faulty process during the formation of the group. Even if they are members, they may be excluded from the functioning of the CFUG because of the domination of village affairs by elite groups, also prevailing in the group dynamics of the CFUG. The poor and excluded usually have little to no voice or influence in decisions regarding village or community affairs. The challenge lies in finding ways of including them in the decision-making of the samiti. The tole concept is based on the idea of animating the poor and excluded within a CFUG by working in the tole with a small group. The advantage of encouraging neighbouring households to work together in groups is that it is relatively easy for them to meet and they often have common needs and interests (LFP, 2005c).

\section{Process of formation and facilitation of tole groups}

As the community facilitators start to work at the tole level, they visit each household to build their awareness and convince them to join with neighbouring households to meet and form a group through which they can discuss their needs and present their interests to the CFUG samiti and assembly. Since some toles are not homogeneous, individuals may choose to form groups based on their interests, well being ranking, or exclusion issues. 
A tole group usually starts by discussing the issues, concerns and needs of households and individuals. The groups then plan how they would like to address these concerns and decide upon what requests they would like to make for support from their CFUG samiti and other service providers. The requests might include a broad range of community development activities, ranging from community infrastructure, such as drinking water and village sanitation, to micro-credit and revolving funds to set up emergency funds or give loans to enable the poorest people to participate in incomegenerating activities. The tole groups provide space for effective representation and participation of the poor and excluded people in the executive committee, strengthen their voice and influence in the decisions and allow for more thorough and comprehensive well-being ranking of the community households so that resources can be channelled effectively and to the most needy. The following statements below provide some examples of such effectiveness:

"I cannot say how the CFUGs were functioning before, but now that we are working at the toles it is very good. We have made small tole groups of women, dalits, and disadvantaged [people]. Thus, tole groups meet and discuss about issues to take to the main samiti. From the tole group, people's awareness is raised so they are more motivated to participate. I don't see any disadvantages to working at the toles. It is becoming easier for dalits and the disadvantaged, because we are all speaking with one voice. This program has raised our awareness and brought opportunities for income. We dalits are very happy" - says Man Bahadur Sundas, the Chairperson of Siddhinagar CFUG.

"We had meetings to discuss who was the poorest at each tole, then in the whole group. Then the ranking was approved in the CFUG assembly. If a poor person wants a loan, he/she asks the tole group, which decides whether the person can manage the livestock." explains Rudra Bahadur Regmi, CFUG Chairperson the way tole concept helps in reaching and benefiting the poor users.
"The tole resolves what problems it can at the tole level, which reduces the pressure on the samiti so that it can deal with more general problems. The people in the tole also feel more responsibility for solving their problems"- Sharmila Mahato, a field-level worker in Sankhuwasabha, explains the effectiveness of the concept in resolving the disputes locally.

\section{Community Forest Land Allocation: A} Mechanism for Increasing Access to Assets

The concept of community forest land allocation

Many Community Forests (CF) have plots of land without forest cover. In the original concept for Community Forestry, it was expected that members of the CFUGs would manage this land as a plantation. However, in reality, the lack of clarity regarding which members would actually do the work has resulted in these pieces of bare land being unmanaged. The idea of $\mathrm{CF}$ land allocation to land poor users to improve their livelihoods evolved from the concept of Leasehold Forestry (LHF) in which areas of barren land in national forests are leased to community members for income generation. $\mathrm{CF}$ Land Allocation is a modification of the LHF concept for Community Forests and is being promoted to facilitate and complement other income-generating activities.

\section{Process of community forest land allocation}

In $\mathrm{CF}$ Land Allocation, members of the CFUG agree to allocate a defined area of the Community Forest for use by a specified group of the poorest community members. Most groups require in-depth discussion and orientation to understand and accept the concept. This social input is essential to help the users make the land allocation concept a reality. The duration of the $\mathrm{CF}$ Land Allocation is usually limited to the duration of the CFUG Operational Plan, usually five or ten years. The shorter duration is also often because the CFUG members are unwilling to offer the land for duration of more than a decade. Though there is no provision in the current Community Forestry guidelines to provide $\mathrm{CF}$ land to individual users for personal use, 
this does not restrict some innovative forest officials to practice this as a pro-poor initiative within the current policy framework.

"Land Allocation is not defined in the Community Forestry legislation, but we can accommodate it in the Operational Plan of the CFUG as a programme for the poor. We describe it as allowing empty land to be used to uplift the poor. So the MFSC does not object. But we cannot give the sub-group a certificate of leasehold or ownership," - explains Mahendra Kumar Chaudhari, District Forest Officer, Myagdi.

"In groups where there are relatively few poor people, land allocation works well, but it is more difficult where there are many poor and scarce resources. We need to convince the rich to give land to the poor; this is where social mobilisation is very important," - adds Mr. Chaudhari on its effectiveness in benefiting the poor.

The purpose of the CF Land Allocation is to promote the effective management of barren land in the Community Forest, increasing its productivity and improving the livelihoods of the poor CFUG members. The following

\section{LESSONS LEARNT}

Understanding the complexities of dealing with the poor and excluded is particularly difficult in Nepal, even more so due to the current conflict situation. We cannot make social and cultural changes overnight to ensure a genuine change in exclusion practices or social norms. All of this takes time; as such, a long-term view is needed. In addition, organisational preparedness is needed to implement and adopt an effective pro-poor and inclusive approach. It includes activities enhancing service providers' own understanding and skills in working with the poor and excluded. More importantly, it requires changes in attitudes and behaviours within the concerned organisations.

\section{Lessons from Working on the Tole Concept}

Tole-level groups allow for representative planning and improved distribution of forest products because the needs and aspirations statement from a user of the land explains the benefits.

"Land Allocation gives us land that only we can use. We protect it and can use the grass to feed our goats. We will go together to cut the grass so that we can all do the same work and get the same amount of grass. When we were starting the group, other people said that the agreement should not be for long and that they also wanted $\mathrm{CF}$ land. The main committee had tole meetings and a general meeting to resolve the problem," said Man Maya B.K., member of a subgroup for goat raising and $\mathrm{CF}$ Land Allocation in Parbat.

Forest User Groups use the well being ranking to select members most in need of support to reduce their poverty. Usually, these households or people have little or no land and fewer sources of income than other CFUG members. The CFUGs often allocate a plot of bare Community Forest land to a small group of users in the poorest wealth rank. These people usually use the land to obtain grass to feed livestock, mostly goats, for plantations of broom grass or fodder and fruit trees, and to carry out other IncomeGenerating Activities (IGAs) (LFP, 2005d).

of the poor and excluded are represented when making decisions on IGA, land allocation, committee formation, subsidies for the poor and excluded, equitable distribution of the forest products, and membership conditions and fees.

Greater representation also strengthens the CFUGs institutionally in terms of transparency and public auditing through improved record keeping and conduct of meetings and general assemblies.

The CFUG also becomes an institution for community development because, with increased membership more representative of the composition of the community, it allows for planning from the grassroots. Besides, through ranking of the community's well being and tole planning, the various community members become more aware of the needs of the poor and excluded. 
Through awareness raising and skill development, the poor and excluded become more empowered, gaining voice, influence, and agency in the functioning of their CFUG. The poorest people develop confidence and may become capable of organising themselves to work as a group to improve their situation. They feel included in the CFUG and feel ownership over the Community Forestry Programme, resulting in increased participation by poor and excluded users in the $\mathrm{CF}$ processes. Gradually, they become more integrated into the larger community.

There may be challenges in convincing the rich and socially advantaged to be sensitive and to "give" benefits and power to the poor and excluded. Though the well-being ranking is a participatory process, the distribution of benefits, such as loans to a few households, may cause tensions that demand careful social mobilisation and facilitation. Most groups require in-depth discussion and orientation to understand and accept the concept. This social input is essential to help the users make pro-poor and inclusive activities a reality.

Another challenge will be that as more groups and people participate in these income generation activities, they will begin to compete with each other in the market and consequently, the prices and benefits for a common product could decrease.

\section{Lessons from Community Forest Land Allocation}

During the documentation of $\mathrm{CF}$ Land Allocation in the "Good Practices" paper (LFP, 2005d) the following lessons were listed:

- The poorest people have an opportunity to access the resources of a piece of land, such as grass and NTFPs, with which to improve their livelihoods.

- Consequently, a Community Forest will have less pressure on the land with forest cover and more effective use of the bare land.

- Through the process of allocating land, the awareness of CFUG members is raised regarding the needs of the poor.

- The poorest people develop confidence and become capable of organising themselves to work as a group to improve their situation. They become more integrated into the larger community.

- If the poor earn income from the land and pay royalties, the CFUG gains income that otherwise would not have been possible if the land was unproductive.

- $\quad$ The poorest members feel included in the CFUG and ownership of the $\mathrm{CF}$ programme. This results in increased participation by poor users in the $\mathrm{CF}$ processes.

\section{CHALLENGES AHEAD AND CONCLUSION}

It is clear from the discussion above that change that does not happen in all three domains of change is not as meaningful as, and will have less impact than, change that occurs in all three domains. Within the LFP programme, there are some good indications of change, for example increased recognition and realisation of social exclusion issues at both macro and micro levels and a willingness to change amongst staff, partners and CFUG members. However, these need to be further strengthened if they are to be fully owned. Many constraints remain in terms of resources, agency preparedness, ability to take risks in the current conflict situation, and current structure of the Ministry of Forests and Soil Conservation and its appropriateness (and willingness) to genuinely address issues of social exclusion.

An ongoing question is whether raising social inclusion issues at the community level is sufficient when the wider socioeconomic and political environment does not facilitate transformation, but rather tends to hinder this. Certainly, there are many instances where the Maoists have indicated that they do not want development programmes meddling in 'social mobilisation' and there have been times when the insurgency has taken precedence over development. Despite these difficulties, continued efforts are needed to roll out pro- 
poor and social inclusion strategies, inclusively targeting communities and individuals to reduce their vulnerability and improve their livelihoods. It is also important to keep working on developing tools and

\section{REFERENCES}

Agarwal, B. 1992. Social Security and the Family: Coping with Seasonality and Calamity in Rural India. Journal of Peasant Studies, 17 (3): 341-412.

Agarwal, B. 1997. Gender, Environment and Poverty Inter links: Regional Variation and Temporal Shifts in Rural India, 197191. World Development 25(1): 23-52.

Agarwal, B. 2000. Conceptualizing Environmental Collective Action: Why Gender Matters. Cambridge Journal of Economics, 24: 283-310.

Agarwal, B. 2001. Participatory Exclusions, Community Forestry and Gender: An Analysis for South Asia and a Conceptual Framework. World Development, 29(10): 1623-1648.

Agarwal, B. 2002. The Hidden Side of Group Behavior: A Gender Analysis of Community Forestry in South Asia. In J. Heyer, F. Stewart and R. Thorp (Eds.), Group Behavior and Development: Is the Market Destroying Cooperation? Oxford: Oxford University Press.

Andersen, J. and Siim., B. 2004. Introduction: The Politics of Inclusion and Empowerment - Gender, Class and Citizenship. In Andersen, J. and Siim, B. (Eds.), The Politics of Inclusion and Empowerment - Gender, Class and Citizenship, New York: Macmillan.

Bhalla, A., \& Lapeyre, F. 1997. Social Exclusion: Towards and Analytical and Operational Framework. Development and Change, 28(3): 413-434.

CBS. 2004. Nepal Living Standard Survey 2003-2004 (Vol I and II). Kathmandu: Central Bureau of Statistics, National Planning Commission Secretariat, His Majesty's Government.

CFD. 2005. Community Forestry Database. Department of Forest, Community Forest Division. methods that help to reach and work with the poorest and excluded and strengthening and sharing the best practices for wider and consolidated outcomes.

DFID. 1999 Sustainable Livelihoods Guidance Sheets. Retrieved from:http://www.livelihoods.org/info/info_g uidancesheets.html

DFID. 2005a. Reducing Poverty by Tackling Social Exclusion: A DFID Policy Paper. UK: Department for International Development.

DFID, 2005b. Livelihood and Social Inclusion (LSI) Reporting Guideline and Key Questions (Draft). Kathmandu: Department for International Development, Nepal.

HURDEC. 2004. Social and Geographical Audit of Six Hill Districts of Livelihood and Forestry Programme (SAGA), Summary Report. Kathmandu: Livelihood and Forestry Programme.

Kandel, B., \& Subedi, R. 2004. Pro-poor Community Forestry: Some Initiatives from the Field. In Twenty Five Years of Community Forestry: Proceedings of the Fourth National Workshop on Community Forestry, (pp. 229-237). Kathmandu: Community Forestry Division, Department of Forest.

Kane1, K. R. 2004. Twenty Five Years of Community Forestry: Contribution to Millennium Development Goals. In Twenty Five Years of Community Forestry: Proceedings of the Fourth National Workshop on Community Forestry, (pp. 4-18). Kathmandu: Community Forestry Division, Department of Forest.

Kanel, K. R., \& Niraula, D. R. 2004. Can Rural Livelihood be Improved in Nepal through Community Forestry? Banko Jankari, 14(1), 19-26.

Lama, A. \& Buchy, M. 2002. Gender, Class, Caste and Participation: The Case of Community Forestry in Nepal. Indian Journal of Gender Studies, 9:1.

LFP, 2005a. Pro-Poor and Social Inclusion Strategy (Draft). Kathmandu: Livelihoods and Forestry Programme. 
LFP, 2005b. Hills Monitoring Report: Findings from the Categorization Study of the Seven Hill Districts. Kathmandu: Livelihood and Forestry Programme.

LFP, 2005c. Tole and Interest Groups for CFUG Activities: Increasing the Voice and Influence of Poor and Excluded People in Community Forestry, Good Practices Paper 3. Kathmandu: Livelihoods and Forestry Programme.

LFP, 2005d. Innovations for Pro-poor Community Forestry: Community Forest Land Allocation, Good Practices Paper. Kathmandu: Livelihoods and Forestry Programme.

Pokhare1, B. \& Nurse, M. 2004. Benefiting the Poor from Community Forestry. Forest and Livelihood, 4(1): 19-29.

Rai, B. (Forthcoming). Agrarian Structures and Distributive Outcomes of Community Forestry in Nepal. The Hague: Institute of Social Studies.

Sunderlin, W. D.; Angelsen, A.; Belcher, B.; Burgers, P.; Nasi, R.; Santoso, L. and Wunder, S. (2005). Livelihoods, Forests, and Conservation in Developing Countries: An Overview. World Development, 33(9): 13831402.

Zanetell, B. A. and Knuth, B. A. 2004. Participation Rhetoric or Community-Based Management Reality? Influences on Willingness to Participate in a Venezuelan Freshwater Fishery. World Development, 32(5): 793-807. 